\title{
Digitally Enabled Sharing and the Circular Economy: Towards a Framework for Sustainability Assessment
}

Pouri, Maria ; Hilty, Lorenz

\begin{abstract}
The prevailing patterns of consumption and production are not sustainable because they are based on increasing extraction of non-renewable resources (such as fossil fuels or scarce metals) from the Earth's crust and overuse of life-sustaining ecosystem services (such as $\mathrm{CO} 2$ assimilation or the water cycle). One strategy to direct consumption to a sustainable pathway is the circular economy. The goal of the circular economy is to slow down the flow of material resources through the anthroposphere and to return them back to nature in a form that is as compatible as possible with the ecosystem processes. We focus on the first aspect, which means that each unit of material resource that enters the economic system should satisfy as much human needs as possible until it is considered waste. We ask the question if and how the emerging "sharing economy" can contribute to this specific goal. We see the phenomenon of sharing economy as a transformation of sharing practices with means of digital Information and Communication Technology (ICT). The resulting Digital Sharing Economy (DSE) can therefore be considered an important special case of ICT impact on sustainable development. We open up an argument on how sharing in the DSE can be either supportive or counter-productive with regard to the circular economy goals. We present a first framework that provides a guideline for the qualitative assessment of new sharing practices with regard to their potential contribution to a circular economy.
\end{abstract}

DOI: https://doi.org/10.1007/978-3-030-30862-9_8

Posted at the Zurich Open Repository and Archive, University of Zurich ZORA URL: https://doi.org/10.5167/uzh-189822

Book Section

Accepted Version

Originally published at:

Pouri, Maria; Hilty, Lorenz (2020). Digitally Enabled Sharing and the Circular Economy: Towards a Framework for Sustainability Assessment. In: Schaldach, Rüdiger; Simon, Karl-Heinz; Weismüller, Jens; Wohlgemuth, Volker. Advances and New Trends in Environmental Informatics. Cham: Springer, 105-116.

DOI: https://doi.org/10.1007/978-3-030-30862-9_8 


\title{
Digitally Enabled Sharing and the Circular Economy: Towards a Framework for Sustainability Assessment
}

\author{
Maria J. Pouri ${ }^{1}$ and Lorenz M. Hilty ${ }^{1,2}$ \\ ${ }^{1}$ Department of Informatics, University of Zurich, Switzerland \\ ${ }^{2}$ Technology and Society Lab, Empa Materials Science and Technology, Switzerland \\ pouri@ifi.uzh.ch,hilty@ifi.uzh.ch
}

\begin{abstract}
The prevailing patterns of consumption and production are not sustainable because they are based on increasing extraction of non-renewable resources (such as fossil fuels or scarce metals) from the earth's crust and overuse of life-sustaining ecosystem services (such as $\mathrm{CO}_{2}$ assimilation or the water cycle). One strategy to direct consumption to a sustainable pathway is the circular economy. The goal of the circular economy is to slow down the flow of material resources through the anthroposphere and to return them back to nature in a form that is as compatible as possible with the ecosystem processes. We focus on the first aspect, which means that each unit of material resource that enters the economic system should satisfy as much human needs as possible until it is considered waste. We ask the question if and how the emerging "sharing economy" can contribute to this specific goal. We see the phenomenon of sharing economy as a transformation of sharing practices with means of digital Information and Communication Technology (ICT). The resulting Digital Sharing Economy (DSE) can therefore be considered an important special case of ICT impact on sustainable development. We open up an argument on how sharing in the DSE can be either supportive or counter-productive with regard to the circular economy goals. We present a first framework that provides a guideline for the qualitative assessment of new sharing practices with regard to their potential contribution to a circular economy.
\end{abstract}

Keywords: Digital Sharing Economy, Circular Economy, Resource Consumption, Sustainability Assessment.

\section{Introduction}

Human society is heavily dependent on the environment. All material goods are made from natural resources in one way or another. The current rates of resource extraction are already a burden on the environment [1]. Therefore, the prevailing consumption and production patterns cannot be considered sustainable, causing depletion of earth's finite resources and degrading the environment [2]. As global population grows and economies expand, consumption will continue to rise.

Encouraging and reaching sustainable consumption is a necessary condition for sustainability as "a situation in which human activity is conducted in a way that con-

\section{This Accepted Author Manuscript is copyrighted by Springer.}

Citation: Pouri, M.J., Hilty, L.M.: Digitally Enabled Sharing and the Circular Economy: Towards a Framework for Sustainability Assessment. In: Schaldach, R., Simon, K., Weismüller, J., Wohlgemuth V. (eds.). Advances and New Trends in Environmental Informatics (pp. 105116). Springer International Publishing (2019). 
serves the functions of the earth's ecosystems" [3]. Only then, sustainable development can be achieved, which meets "the needs of the present without compromising the ability of future generations to meet their own needs" [4]. Gaining traction as an approach to achieve sustainable development [5], the vision of a circular economy is now being widely discussed in academic literature as well as in policy-making and executive domains.

The circular economy has positive effects on some aspects of sustainability [6]; its vision and approach ensure that products are being used with a better utilization over time [2]. The circular economy is "an industrial economy that is restorative or regenerative by intention and design" ([7], p. 14). It refers to the "design and business model strategies [that are] slowing, closing, and narrowing resource loops" ([8], p.309). With respect to sustainability, the circular economy “... aim(s) to accomplish sustainable development, which implies creating environmental quality, economic prosperity and social equity, to the benefit of current and future generations." ([9], p.225) ${ }^{1}$.

While such approaches intend to align consumption patterns with sustainability objectives, technological advancements and the application of digital Information and Communication Technology (ICT) in everyday life changes the consumption trends of individuals and societies. While the transformational power of ICT can make production and consumption patterns more sustainable, the efficiencies brought by the technological advancement do not "automatically" contribute to sustainable development [12].

The digital transition of societies and economies has downsides too [13]. As ICT brings efficiency, the demand for its efficiently produced solutions may become stimulated to a degree that can offset the theoretically possible savings partially or even entirely [12]; this phenomenon is called the "rebound effect" and has been widely discussed in studies on ICT-induced efficiencies and systems' responses to them (e.g. $[14,15])$.

An important example of the transformative power of ICT on consumption is the digitally enabled sharing economy, or 'Digital Sharing Economy' (DSE) for short. The growth and popularity of the DSE is much due to its enabling individuals to connect and develop peer networks ('peer' in the sense of someone having similar needs) for engaging in sharing regardless of time, place, communication, and coordination limits, as it holds true for many activities in the digital world. This dynamic, collaborative participation ('dynamic' in the sense of active involvement and 'collaborative' in the sense of collective responsibility of the participating population) allows a large number of peers to gain a share of what others already own or offer, and to enjoy the economic and social benefits of sharing depending on their individual needs.

From a circular economy perspective, the act of sharing has a potential to increase the ratio of satisfied human needs per amount of natural resources needed (i.e., to increase resource efficiency) and is thus compatible with sustainability objectives.

1 For more on the conceptual relations between the two concepts of circular economy and sustainability, see [10]. For more on the relevance of the circular economy for sustainability and for the implementation of the Sustainable Development Goals (SDGs), see [5, 11]. 
However, unintended effects of the digitally enabled sharing should be taken into consideration too. As the authors argue in an earlier article [16], if any product or service in the DSE becomes cheaper, faster or more convenient to access, the usual reaction of a market is an increase in the demand for it, which may ultimately balance out the favorable effects of shared consumption within the same product/service system (direct rebound effect). It may also be the case that the time or money saved due to sharing is spent on consuming other products or on using a service which is less resource-efficient (indirect rebound effect) [16]. Taking this into account, the potential contribution of the DSE to create and support a circular economy through maximized resource efficiency needs to be addressed with more reflection.

The implications of extensive sharing practices from a circular economy or a general sustainability perspective have not been much discussed by the existing studies. Literature lacks an integrated approach to explain the relevance of sharing for sustainability, in particular with respect to circular economy objectives. In this paper, we present a first framework for supporting sustainability assessment of the DSE by looking at the scenarios created by it and evaluating them from the perspective of the circular economy.

The remainder of this paper is structured as follows: In Section 2, we address the relevance of the sharing practices used in the DSE for the circular economy. Section 3 reviews the definition, system's characteristics, and resources in platform-based sharing. Building on the system's specifications and considering the 'circularity' implications of extensive sharing, we will in Section 4 conduct an analysis of optimized consumption (as a desirable effect of sharing) and possible induction effects and rebound effects (as counter-productive effects of sharing from a circular economy perspective) in the context of sustainability. Sections 5 and 6 are devoted to further discussion and the conclusion.

\section{The relevance of sharing for the circular economy}

To reach a circular economy, Bocken et al. [8] specify the following strategies: slowing resource loops, closing resource loops, and resource efficiency or narrowing resource flows. As further explained by Bocken and colleagues, through the design of hard-wearing and long-life products, the utilization period of them becomes prolonged and this extended product life slows the resource loops over time; this slowdown corresponds to reduction in the rate of resource input flow. Closing loops between post-use and production phases means to recycle products after their end-oflife, hence enabling a circular flow of resources with minimum waste [17]. By narrowing loops, fewer resources will be used per products and production processes.

While much emphasis is put on strategies towards product design ${ }^{2}$, achieving a slowdown is also influenced by consumer involvement in schemes that increase the utilization of products, such as sharing schemes [21]. Shared consumption is a prime

2 For more on product design for circular economy, see [8, 18-20]. 
example of and an important vision for product reuse [22]. Before the application and proliferation of digital platforms, there was a low profile of sharing systems in society and on the market [23]. However, with the expansion of the ICT-enabled, platformbased sharing economy (i.e. the DSE), this low profile grew along with the growth of sharing in almost every aspect, including the size of networks, scale of performance, diversity of resources and services, complexity of coordination and allocation, viability of transactions, etc. [24]. Platforms are now endorsing a massive amount of transactions and operations in the DSE, locally and even worldwide.

The relevance of the sharing practices performed via digital platforms for the circular economy and product reuse has been already expressed in literature (e.g., [22, 25]. Sharing platforms can potentially help to slow down resource flow by enabling access to existing products [25]. Being an important enabler of the circular economy, the DSE can bring about significant improvements in resource efficiency as sharing can put the highest possible utilization capacity of the existing products into a more efficient use [22]. However, platform-based sharing also tends to use and sustain the current unsustainable infrastructures to serve the market [25] while even promoting unsustainable consumption trends [26].

In the following sections (after describing the DSE in some more detail), we will propose a framework for sustainability assessment of the sharing trend that is evolving in the DSE, focusing here on the sustainability implications of sharing with respect to the circular economy strategies. This framework aims to present the implications of the DSE for sustainability by projecting possible scenarios describing how the DSE can support or hinder a transition towards a circular economy.

\section{The Digital Sharing Economy (DSE)}

"The digital sharing economy (DSE) is a class of resource allocation systems based on sharing practices which are coordinated by digital online platforms and performed by individuals and possibly commercial organizations with the aim to provide temporary access to resources without transfer of ownership while generating monetary or non-monetary value for the participants. Digital sharing systems operate in the space between traditional sharing and formal markets" [24].

In order for sharing to be viable, resources must be sharable across the system. Previous studies have classified sharable resources in 'tangible' vs. 'intangible' resources [27], 'material goods' vs. 'less-tangible assets' [28], and 'capacityconstrained' vs. 'capacity-unconstrained' assets [29]. We draw on the classification of resources as tangibles and intangibles. For the purpose of this study, we will focus only on tangible ones because they are based on material resources.

Tangible resources are further divided into durables and non-durables (or consumables). The reason for distinguishing between durable and non-durable resources is because of the difference in the way they are shared. By being 'sharable', a resource should be 'durable enough' to endure multiple access (either in sequence or in parallel). For a non-durable (consumable) resource, there is no repeated access to a given 
part of it: consumables (such as food, fuel, etc.) are exhausted once consumed. Yet, such resources and the act of consuming them can be shared (traditionally, as food is consumed in groups).

In addition to giving access to sharable resources, the instances of the DSE usually have some typical characteristics:

Low entry barrier: The DSE provides an open and easy-to-participate network for its users and in many cases (if not all); the entry barriers for participants are considerably lower in digital sharing systems compared to the formal markets to offer the same services. This is at least true for people who are using digital technologies such as a smartphone anyway. Having possession of a physical asset or a particular skill to offer as a service, a smartphone, installing an application, and agreeing to a platform's regulations normally suffice to be a resource/service provider in the system (in cases, membership fees may be also applied). ${ }^{3}$

Value co-creation: In contrary to service provision by businesses in the formal market, in which a business is the only entity that creates and offers value to its customers, value in the DSE can also be created by its participants, leading to value cocreation [33]. In this context, platforms act as tools to enable and facilitate value cocreation across the system while being the 'medium' for value exchange. This value co-creation (both in P2P and B2P sharing modes) shifts the responsibility of many tasks which are normally undertaken by businesses to peers, rather than requiring platform owners to endorse all aspects of service provision from their own resources [24].

Lower prices: Being a 'cross-market' operating between the two extremes of the traditional sharing and the formal market, the DSE's pricing mechanisms should allow for a range from free services (an attribute taken from the traditional sharing closer to and including the lower extreme) to services that enforce a certain type of compensation, including fee-based services (an element of the formal market - closer to and 'never' reaching the upper extreme) [24]. In the DSE, the cost of receiving services should be lower than their equivalent provided by companies acting in the formal market, if such a market exists. By theory, prices for the DSE services should remain lower than their equivalent in the formal market (always below the upper extreme) [24].

\section{Conceptualizations of ICT effects on sustainability}

Through lenses of sustainability, ICT can have positive and negative effects on patterns of consumption and production. Existing literature presents various approaches and frameworks to reflect on the role of ICT in society's transition towards sustainability ${ }^{4}$. An early framework in this area was proposed by Berkhout and Hertin in 2001

3 Entry barriers have been argued to have created inequality in terms of requiring possessing an asset or skill to enter the platform-based labor market [30].

4 For an overview of conceptual frameworks for structuring effects of ICT on sustainability, see [31]. 
[32], first introducing the "three order of effects" model. This basic model was extended and further developed by many authors, including Dompke et al. [33] and Hilty and Aebischer [12]. It has also been combined with early work done by Moktharian et al. [34] on the relationships between telecommunications and transportation. We will apply, as a common core of these approaches, the following three categories of effects to analyze the ambivalent impact of the DSE on the circular economy: optimization effects, induction effects and rebound effects.

Technology has a huge potential to increase efficiency-i.e., efficient use of resources such as energy, time, effort, etc.- by optimizing consumption and production processes [12]. As a result of the optimization, costs involved in doing an activity can decrease remarkably (a driver can optimize the route to take from A to B by using a navigation system, thus saving fuel and time). However, with an increase in efficiency and a corresponding decrease in costs, existing consumers can afford more consumption while new consumers are enabled to enter the consumption chain too. When the demand rises and, as a consequence, consumption rate goes beyond the availabilities, the system starts revealing unintended countereffects known as "rebound effects". Rebound effects prevent the reduction of total resource use by converting efficiency improvements into additional consumption and ultimately lead to (partially or entirely) offsetting the initial efficiencies and positive effects [12].

"Efficient technologies can also stimulate the demand for the resource they use efficiently" ([12], p. 5). This means that through an induction effect [12], the consumption of other resources, which are required for an efficient resource, can become stimulated too (the use of electricity increases in order to charge more and more efficient, electric devices).

In the following, we address the above effects for the DSE as a use case of ICT. These effects comprise our framework for a qualitative assessment of the sustainability of the DSE with an approach to the circular economy.

Induction effects are, like rebound effects, unintended side effects of introducing an ICT-based solution leading to higher resource consumption. However, in contrast to rebound effects, they are not specifically explainable as a reaction to higher efficiency. This will become more clear when we will apply these concepts in the next section.

\section{$5 \quad$ Qualitative sustainability assessment of digital sharing}

The DSE is a technological innovation [16] that has changed consumption preferences; it has shifted parts of consumption from an ownership-transfer mode to an access-based mode. The affordable (low cost/free), accessible (via a smart phone), and convenient (real-time information at fingertips) consumption of services through platform-based sharing has made it possible for people to access a vast variety of resources. Consumers are provided with temporary access to a resource that otherwise they would have needed to purchase on the formal market (e.g. borrowing a household tool from a neighbor); or access to resources that are less expensive or even free compared to their equivalent in the formal market (e.g. booking a room from a host on 
Airbnb $^{5}$ instead of booking one from a hotel, or to receive free hospitality services from Couchsurfing $\left.{ }^{6}\right)$. Coordination of this access is enabled by ICT-based platforms making it possible to spot the available resources for being utilized at any given time, and providing access in seconds.

Like in any other application domain, the effects of introducing ICT can be analyzed using the concepts introduced in Section 4.

Optimization effect: Owners can help slowing down resource flow by sharing the unused capacity of their owned products with others, allowing resources to remain in the use phase for a longer time (or, more precisely, making resources provide more utility over their lifetime) by not being stored away most of the time or by being disposed of at an earlier stage $[21,35,36]$. With each act of sharing, parts of the unused capacity of a particular resource come into use. The underlying idea of sharing is that "whenever a user has some idle resource, she offers it to other users who at that time have unsatisfied needs ... Such solutions can improve resource efficiency." ([37], p. 1). This efficient use, facilitated by ICT-enabled platforms, is in fact an optimization of the consumption process. For example, when a person uses a carpooling service, more people (up to the capacity of the car) can ride the same car, and therefore the number of functional units (here defined as one person kilometer) created on the trip (and therefore the utility created) increases. For car sharing (more people owning the same car, but not at the same time) or ride services (such as Uber $^{7}$ ), the car can produce more person kilometers by transferring more people over its lifetime. This is possible because its idle time (which will nevertheless involve some form of aging) will be reduced. Therefore, in the DSE, optimization occurs through improved utilization of available resources during their lifetime. What is to be optimized is the number of functional units produced throughout the whole use phase (lifetime) of the resource.

Rebound effects: If any product or service becomes faster, cheaper or more convenient to access, a usual reaction of the market to this increased efficiency is an increase in the demand for that good. This may ultimately balance out the favorable effects of shared consumption within the same product/service system (direct rebound effect); or it can happen that the savings (time or money) gained from sharing is spent on other consumption which is even more resource-intensive (indirect rebound effect) [16]. Rebound effects can lead to additional resource inflow of natural resources into the system (e.g. for the millions of e-scooters now produced to be used in freefloating sharing systems in cities): a situation that is in contrast with the notion of a circular consumption and the strategies to achieve a slowdown in and narrowing resource loops.

Special attention is to be given to time rebound effects when considering the sustainability of technology-based efficiency gains [38]. Time rebound comes from a decline in the time needed to acquire and consume a service; this reduces the explicit

\footnotetext{
${ }^{5}$ https://www.airbnb.com/

${ }^{6} \mathrm{https}: / /$ www.couchsurfing.com/

${ }^{7}$ https://www.uber.com/ch/en/
} 
or implicit costs associated with time [13]. Owing to the efficiency of platforms in matching needs with availabilities (e.g. locating the nearest available car), the consumer can save time; this saved time can be spent on consuming more of the same or another service, or on some other activity with high resource intensity.

Therefore, through lower costs associated with resource access and utilization in the DSE, rebound effect can cancel out the efficiencies and savings gained from the sharing system. It is even suggested that "the overall effects of sharing economy platforms may be small due to rebound effects." [39, p. 8].

Induction effect: Any consumption, including the use of a shared resource, can stimulate the consumption of other resource(s). One could speak of 'coupled consumption'. Back to the example of car sharing and riding services, in order for a car to operate, it requires fuel and temporary occupation of a part of the infrastructure (i.e. roads); without these complementary resources, using a car as a means of transportation could not produce its service. These complementary resources must be taken into account when assessing the overall effect of different sharing schemes. For example, for carpooling not only the car, but also the complementary resources of using the car can be divided by the number of passengers. This is, however, not the case for car sharing or ride services. Studies on the impact of the growth of platform-based ride services in San Francisco [40] and New York City [41] indicate adverse effects on urban traffic. Uber and Lyft are known to account for "more than half of San Francisco's real-world traffic increase" [40]. As Fox [40] further reports, from 2010 to 2016, these ride sharing services increased the time cars spend sitting in the city's traffic by around $70 \%$. The study of the New York City echoes similar findings. Schaller [41] introduces the platform-based riding services as a leading source of increase in non-personal auto travel in the city, and as "not a sustainable way to serve the growing transportation needs generated by the city's expanding population and economic activity." (p. 26). Since building and maintaining infrastructures is one of the most resource-intensive activities of urban societies, the fact that a sharing system occupies an increased share (!) of this infrastructure per functional unit is clearly in contradiction to the goals of a circular economy.

\section{Discussion}

We have shown that induction and rebound effects have to be taken into account to see if the optimized consumption achieved by new practices of sharing in the DSE actually contributes to the goals of the circular economy - the final outcome of these effects may be different for each instance of the DSE and requires a closer look at the resource flows and demand dynamics in each case.

Besides the 'classical' impact categories of optimization, induction, and rebound effects, there is another aspect we want to introduce because it is closely linked to the vision of the circular economy, the aspect of asset degradation. Multiple access raises a relevant consideration regarding product lifetime becoming shorter as a result of the product's faster degradation. As pointed out by Weber [42], shared use of a product degrades it faster. Degradation by intensified wear and tear (as it can be observed, 
e.g., with shared bicycles or e-scooters) counteracts the optimization effect from a life cycle perspective. Faster degradation corresponds to higher replacement costs [42] and apparently new resource inflows. Although approaches to this problem can be to embed justified prices for sharing and to set activities that extend the service life of the products (such as maintenance and repairs) [42], the importance of product design remains significant with respect to the DSE becoming a viable approach to achieve a circular economy.

In addition to strategies for product design and lifetime extension, consumers play an important role in driving products' lifetime [18, 21, 43]. In the DSE, user behavior is to a large degree both influenced by and influencing the services in the system. With respect to the users' influence, setting sustainable consumption patterns cannot be achieved without consumers' attitudes to support sustainability [44], and the circular economy as a particular approach to it. With people being more and more willing to and cautious about 'circular choices', service providers can capture their considerations and preferences to move their services into the direction of a more circular, sustainable economy. It is also important to explore whether it is more important for consumers to practice sustainable sharing, or just to take economic benefits from sharing. When the DSE reaches a point where sharing may not be sustainable anymore, will people refrain from participating? It remains important to investigate to what extent individual motivations and user behavior incorporate environmental considerations in their choices for consumption [45].

On the influence of services on user behavior, we may point out the role of service providers in encouraging desirable behaviors. According to Tukker [46], it is highly plausible that people treat products that they do not own with less care; this in some cases may lead to higher environmental impacts (for example by increasing the need for frequent product replacements). To deal with such undesired behaviors, providers can enforce some regulations to be observed by receivers of their services (for example, Zipcar requires its users to take care of the cars and to return them clean and undamaged as regulations for using its services). Users' engagement can correspond with value co-creation in consuming services. This value co-creation involves consumers in keeping products in better status (in the sense of better maintenance and utilization) so that to extend products useful utilization Whether the users are motivated to such engagement might also depend on the business model of the system: Is the business model still based on the idea of the common good, or is the provider a company that has the only goal to grow its profits?

\section{Conclusion}

The intensified utilization of resources in the DSE motivates new consumption trends while raising discussions about the sustainability implications of the digitally enabled sharing and its contributions to the circular economy, as an approach to achieve sustainability. We tried to shed light on the relevance of platform-enabled sharing practices for sustainability and circular economy goals through presenting a qualitative assessment framework. Based on this framework, optimization in consumption, in- 
duction effects and rebound effects are the potential implications of the DSE in the context of sustainability and as an approach to support circular economy goals.

To summarize, although sharing by itself has positive effects on the efficiency of resource use, the extensive platform-based sharing practices should be checked for undesired side effects in terms of resource flows:

- The basic objective function in the system should be the number of functional units (also known as 'service units') delivered over the use phase of the resources bound for the purpose of producing the service. This objective function goes up by shared use but is also driven down by the faster degradation of products that can occur as the result of large-scale, relatively anonymous and profit-oriented sharing systems.

- Not only the shared resource itself, but also coupled consumption activities (e.g. the use of complementary products such as fuels or infrastructure capacity) should be taken into account to get the whole picture. If all resources needed are considered, sharing one of them at the cost of the others may not necessarily contribute to sustainability. For example, the travel induced by Couchsurfing should be included in a sustainability assessment of this platform.

- The risk of direct or indirect rebound effects that in the end lead to increasing resource flows must be taken into account. Investments in additional assets (to be shared) may indicate that there is a rebound effect (e.g. when appartments are acquired just to 'share' them on Airbnb). Investors will understand increasing demand not as rebound effect, but as expected growth.

\section{References}

1. Swiss Federal Office for the Environment: https://www.bafu.admin.ch/bafu/en/home.html

2. Velenturf, A., Purnell, P., Tregent, M., Ferguson, J. and Holmes, A.: Co-producing a vision and approach for the transition towards a circular economy: perspectives from government partners. Sustainability, 10(5), p.1401 (2018).

3. International Organization of Standardization. ISO 15392: 2008 Sustainability in building construction - General principles, ISO Geneva (2008).

4. WCED, World Commission on Environment and Development: Our common future. Oxford: Oxford Univ. Press. (1987).

5. Schroeder, P., Anggraeni, K. and Weber, U.: The relevance of circular economy practices to the sustainable development goals. Journal of Industrial Ecology, 23(1), pp.77-95 (2019).

6. Murray, A., Skene, K. and Haynes, K.: The circular economy: An interdisciplinary exploration of the concept and application in a global context. Journal of Business Ethics, 140(3), pp.369380 (2017).

7. Ellen MacArthur Foundation: Towards the circular economy Vol. 2: Opportunities for the consumer goods sector: https://www.ellenmacarthurfoundation.org/assets/downloads/publications/Ellen-MacArthurFoundation-Towards-the-Circular-Economy-vol.1.pdf

8. Bocken, N.M., de Pauw, I., Bakker, C. and van der Grinten, B.: Product design and business model strategies for a circular economy. Journal of Industrial and Production Engineering, 33(5), pp.308-320 (2016). 
9. Kirchherr, J., Reike, D. and Hekkert, M.: Conceptualizing the circular economy: An analysis of 114 definitions. Resources, Conservation and Recycling, 127, pp.221-232 (2017).

10. Geissdoerfer, M., Savaget, P., Bocken, N.M. and Hultink, E.J.: The Circular Economy-A new sustainability paradigm?. Journal of cleaner production, 143, pp.757-768 (2017).

11. Berg, A., Antikainen, R., Hartikainen, E., Kauppi, S., Kautto, P., Lazarevic, D., Piesik, S. and Saikku, L.: Circular Economy for Sustainable Development, REPORTS OF THE FINNISH ENVIRONMENT INSTITUTE 26 (2018).

12. Hilty, L.M.; Aebischer, B.: ICT for Sustainability: An Emerging Research Field. In ICT Innovations for Sustainability; Hilty, L.M., Aebischer, B., Eds.; Springer International Publishing: Cham, Switzerland; pp. 3-36 (2015).

13. Coroamă, V.C. and Mattern, F.: Digital Rebound-Why Digitalization Will Not Redeem Us Our Environmental Sins (2019).

14. Hilty, L.M.; Köhler, A.; von Schéele, F.; Zah, R.; Ruddy, T.: Rebound Effects of Progress in Information Technology. Poiesis Prax., 4, 19-38 (2006).

15. Gossart, C.: Rebound Effects and ICT: A Review of the Literature. In ICT Innovations for Sustainability, Advances in Intelligent Systems and Computing; Springer International Publishing: Cham, Switzerland, pp. 435-448 (2015), ISBN 978-3-319-09227-0.

16. Pouri, M.J. and Hilty, L.M.: Conceptualizing the Digital Sharing Economy in the Context of Sustainability. Sustainability, 10(12), p.4453 (2018).

17. Bourguignon, D.: Closing the loop: New circular economy package. European Parliamentary Research Service, p.9 (2016).

18. Van den Berg, M.R.; Bakker, C.A.: A product design framework for a circular economy. In Proceedings of the PLATE Conference, Nottingham, UK, 17-19 June 2015; pp. 365-379.

19. Moreno, M.; de los Rios, C.; Charnley, F.: Guidelines for Circular Design: A Conceptual Framework. Sustainability, 8, 937 (2016).

20. den Hollander, M.C.; Bakker, C.A.; Hultink, E.J.: Product Design in a Circular Economy: Development of a Typology of Key Concepts and Terms. J. Ind. Ecol., 21, 517-525 (2017).

21. Wastling, T., Charnley, F. and Moreno, M.: Design for circular behaviour: considering users in a circular economy. Sustainability, 10(6), p.174 (2018).

22. Korhonen, J., Honkasalo, A. and Seppälä, J.: Circular economy: the concept and its limitations. Ecological economics, 143, pp.37-46 (2018).

23. Mont, O.: Institutionalisation of sustainable consumption patterns based on shared use. Ecological economics, 50(1-2), pp.135-153 (2004).

24. Pouri, M.J., Hilty, L.M.: A theoretical framework for the digital sharing economy. Author manuscript.

25. Konietzko, J., Bocken, N. and Hultink, E.J.: Online Platforms and the Circular Economy. In Innovation for Sustainability (pp. 435-450). Palgrave Macmillan, Cham, (2019).

26. Martin, C.J.: The sharing economy: A pathway to sustainability or a nightmarish form of neoliberal capitalism?. Ecological economics, 121, pp.149-159 (2016).

27. Pouri, M.J. and Hilty, L.M.: ICT-Enabled Sharing Economy and Environmental Sustainability-A Resource-oriented Approach. In Advances and New Trends in Environmental Informatics (pp. 53-65). Springer, Cham, (2018).

28. Ranjbari, M., Morales-Alonso, G. and Carrasco-Gallego, R.: Conceptualizing the sharing economy through presenting a comprehensive framework. Sustainability, 10(7), p.2336 (2018).

29. Wirtz, J., So, K.K.F., Mody, M., Liu, S. and Chun, H.: Platforms in the Peer-to-Peer Sharing Economy, (2019).

30. Schor, J.B.; Attwood-Charles, W. The "sharing" economy: Labor, inequality, and social connection on for-profit platforms. Sociol. Compass 2017, 11, e12493 
31. Hilty, L.M. and Lohmann, W.: An annotated bibliography of conceptual frameworks in ICT for sustainability. Ict4S, 3013, pp.14-16 (2013).

32. Berkhout, F. and Hertin, J. 2001. Impacts of Information and Communication Technologies on Environmental Sustainability: Speculations and Evidence. Report to the OECD. http://www.oecd.org/dataoecd/4/6/1897156.pdf

33. Dompke, M., von Geibler, J., Göhring, W., Herget, M., Hilty, L. M., Isenmann, R., Kuhndt, M., Naumann, S., Quack, D. and Seifert, E. 2004. Memorandum Nachhaltige Informationsgesellschaft. Fraunhofer IRB, Stuttgart 2004, ISBN: 3-8167-6446-0

34. Mokhtarian, P. L.: A Typology of Relationships between Telecommunications and Transportation. Transportation Research Part A: General 24 (3), 231-242 (1989).

35. Wilson, G.T.; Smalley, G.; Suckling, J.R.; Lilley, D.; Lee, J.; Mawle, R.: The hibernating mobile phone: Dead storage as a barrier to efficient electronic waste recovery. Waste Manag, 60, 521-533 (2017).

36. The Waste and Resources Action Programme (WRAP). Switched on to Value: Powering Business Change; WRAP: Oxford, UK, 2017.

37. Georgiadis, L., Iosifidis, G. and Tassiulas, L.: On the Efficiency of Sharing Economy Networks. IEEE Transactions on Network Science and Engineering, (2019).

38. Binswanger, M.: "Technological progress and sustainable development: what about the rebound effect?," Ecological Economics, vol. 36, no. 1, pp. 119-132 (2001).

39. Frenken, K. and Schor, J.: Putting the sharing economy into perspective. Environmental Innovation and Societal Transitions, 23, pp.3-10 (2017).

40. Fox, A., 2019: https://www.sciencemag.org/news/2019/05/uber-and-lyft-may-be-making-sanfrancisco-s-traffic-worse

41. Schaller, B.: Unsustainable? The growth of app-based ride services and traffic, travel and the future of New York City. Schaller Consulting. (2017).

42. Weber, T.A.: The Dynamics of Asset Sharing and Private Use. In Proceedings of the 51st Annual Hawaii International Conference on System Sciences (HICSS), Waikoloa Village, HI, USA, 3-6 January 2018; pp. 5205-5211.

43. Mugge, R.; Schoormans, J.P.L.; Schifferstein, H.N.J.: Design Strategies to Postpone Consumers' Product Replacement: The Value of a Strong Person-Product Relationship. Des. J. 2005, 8, 38-49.

44. Hamari, J., Sjöklint, M. and Ukkonen, A.: The sharing economy: Why people participate in collaborative consumption. Journal of the Association for Information Science and Technology , 67(9), pp.2047-2059 (2015).

45. Demailly, D.; Novel, A.S.: The Sharing Economy: Make it Sustainable; IDDRI: Paris, France; Volume 3 (2014).

46. Tukker, A.: Product services for a resource-efficient and circular economy-A review. J. Clean. Prod., 97, 76-91 (2015). 